\title{
EFEITO DE ÓLEOS ESSENCIAIS SOBRE A ENZIMA UREASE: UM ESTUDO IN VITRO E IN SILICO
}

\section{EFFECT OF ESSENTIAL OILS ON UREASE ENZYME: IN VITRO AND IN SILICO STUDY}

Deisiane Aparecida da Silva ${ }^{1}$, Flavianny Brencis da Silva Mikalouski ${ }^{2}$, Rubia Michele Suzuki ${ }^{2}$, Rafaelle Bonzanini Romero ${ }^{1}$, Adriano Lopes Romero $^{1}$

\footnotetext{
${ }^{1}$ Universidade Tecnológica Federal do Paraná, Departamento Acadêmico de Química, Campo Mourão, Paraná. '2Universidade Tecnológica Federal do Paraná, Departamento Acadêmico de Química, Apucarana, Paraná. Agência de fomento: Fundação Araucária

e-mail: adrianoromero@utfpr.edu.br
}

RESUMO - O objetivo deste estudo foi realizar estudos in vitro e in silico com óleos essenciais visando à busca de substâncias bioativas inibidoras de urease com potencial atividade anti- $H$. pylori. A metodologia para os estudos in vitro baseou-se na utilização da urease de soja, escolhida como um sistema modelo para estudar o efeito de potenciais inibidores de urease. Os constituintes majoritários dos óleos essenciais avaliados foram submetidos a estudos de ancoragem molecular frente a enzima urease (PDB 1E9Z). Os resultados obtidos sugerem que os compostos eucaliptol, geranial e D-limomeno podem atuar como inibidores de urease por interagir no sítio ativo da enzima. Conclui-se que os óleos essenciais podem ser considerados fontes promissoras de substâncias bioativas com efeito inibitório sobre a enzima urease de $H$. pylori.

Palavras-chave: Óleos Essenciais; Urease; Inibição Enzimática; Estudo In Silico; Helicobacter Pylori.

ABSTRACT - The objective of this study was to perform in vitro and in silico studies with essential oils in order to search bioactive substances with potential anti-H. pylori activity. The methodology for in vitro studies was based on the use of soy urease, chosen as a model system to study the effect of potential inhibitors of urease. The major constituents of the evaluated essential oils were subjected to studies of molecular docking with the urease enzyme (PDB 1E9Z). The results suggest that eucalyptol, geranial and D-limomene can act as urease inhibitors to interact in the active site of the enzyme. This study

Recebido em: 19/08/2015 Revisado em: 31/08/2015 Aprovado em: 08/09/2015 concludes that essential oils can be considered promising sources of bioactive substances with inhibitory effect on $H$. pylori urease activity. Keywords: Essential Oils; Urease; Enzymatic Inhibition; In Silico Study; Helicobacter Pylori. 


\section{INTRODUÇÃO}

Desde sua identificação por Marshall e Warren (1982), o Helicobacter pylori rapidamente se tornou alvo de incontáveis estudos microbiológicos, histológicos, epidemiológicos, imunológicos, ecológicos e clínicos. Consequentemente, em curto período de tempo, os avanços do conhecimento na área puderam ser utilizados, de forma revolucionária, na prática médica diária de clínicos e gastroenterologistas (COELHO; ZATERKA, 2005). A descoberta do $H$. pylori revolucionou os conceitos fisiopatológicos das patologias gastroduodenais, como a gastrite, a doença ulcerosa péptica, a neoplasia gástrica e o linfoma MALT (PINTO, 2007). Segundo Souza (2013) esta bactéria é capaz de facilitar a fixação no estômago, induzir uma lesão mucosa e evitar a defesa do hospedeiro, sendo assim, considerada uma das bactérias mais prejudiciais ao organismo.

Com a evolução do gênero o $H$. pylori desenvolveu estratégias que lhe permitem sobreviver e persistir na mucosa gástrica, regulando negativamente a resposta imune do hospedeiro através dos seus fatores de virulência (COELHO, 2013). A resistência ao ácido clorídrico presente no estômago é de vital importância na patogênese do $H$. pylori, visto que, sem este atributo biológico, a bactéria não teria condições de colonizar a mucosa gástrica (LADEIRA, 2003). Este mecanismo de sobrevivência é atribuído a potente atividade da enzima urease (SIQUEIRA, 2007). Esta enzima, que é uma proteína de alto peso molecular (500 a 600 $\mathrm{kDa}$ ), atua promovendo a hidrólise da uréia, presente em condições fisiológicas no suco gástrico, levando à produção de amônia e dióxido de carbono. A amônia produzida atua como receptor de íons $\mathrm{H}^{+}$, tornando $\mathrm{o} \mathrm{pH}$ neutro no interior da bactéria, o que confere ao $H$. pylori resistência à acidez gástrica. Desta maneira, a bactéria fica protegida dos efeitos deletérios do pH ácido do estômago.

Perante tal problemática, muitas razões movem os prescritores a recomendar abusivamente o uso de antibióticos. A grande disponibilidade desses medicamentos, acompanhada de publicidade pouco judiciosa, finda por acentuar o seu uso abusivo. Com isso se mantêm ou agravam as doenças infecciosas, aparecem mais reações adversas, usam-se alternativas antimicrobianas mais onerosas e se produzem mais hospitalizações. Portanto, torna-se imprescindível a necessidade de encontrar, desenvolver, e introduzir no arsenal médico, modalidades terapêuticas mais eficientes que possam oferecer aos pacientes com doenças distintas, novas oportunidades de tratamento que visem melhorias na erradicação de bactérias. Nesta modalidade, os produtos naturais surgem 
como fortes contribuintes no tratamento de enfermidades.

Harvey (2008) reporta os produtos naturais como a fonte da maioria dos ingredientes ativos de medicamentos, sendo amplamente aceitos desde a descoberta de drogas, onde mais de $80 \%$ dos fármacos eram produtos naturais ou inspirados por um composto natural. Ao estabelecer comparações das informações apresentadas sobre as fontes de novos medicamentos entre 1981-2007, os autores observaram que aproximadamente metade dos medicamentos aprovados desde 1994 eram baseadas em produtos naturais.

Diante deste cenário, torna-se fundamental o conhecimento sobre a eficácia das diferentes terapêuticas para a erradicação da H. pylori. Neste contexto, este trabalho teve como finalidade realizar estudos in vitro e in silico com óleos essenciais visando à busca de substâncias bioativas inibidoras de urease com potencial atividade anti- $H$. pylori, apresentando-se como uma alternativa ao uso de antibióticos convencionais.

\section{METODOLOGIA}

Para a obtenção da urease, triturou-se em um liquidificador, $10 \mathrm{~g}$ de soja em $100 \mathrm{~mL}$ de água destilada. Em seguida, utilizando o método tradicional de filtração o extrato foi filtrado e a solução obtida foi diluída em um fator de 200. O filtrado obtido foi utilizado, sem purificações adicionais, como fonte de urease nos testes de inibição enzimática.

Para utilização dos óleos essenciais, foram preparadas soluções acetônicas em sete concentrações distintas 6,$25 ; 12,5 ; 25$; 50; 100; 150 e 250 ppm. Como controle optou-se pelo uso de solução acetônica de tiouréia, considerada um inibidor de urease, nas mesmas concentrações.

O procedimento experimental para determinação da atividade inibidora de urease seguiu o procedimento proposto por Weatherburn (1967). Em cada tubo de ensaio foram colocados $100 \mu \mathrm{L}$ de solução urease, $100 \mu \mathrm{L}$ da solução do óleo essencial a ser testado e $100 \mu \mathrm{L}$ de solução de uréia $6 \mathrm{~g} / \mathrm{L}$. 0 tubo foi mantido em banho-maria na

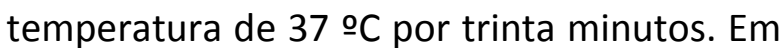
seguida acrescentou-se $500 \mu \mathrm{L}$ dos reagentes A e B. O tubo foi novamente mantido na mesma temperatura por mais trinta minutos. Após o tempo indicado realizou-se leituras em um espectrofotômetro UV-VIS (PG Instruments, modelo $\mathrm{T} 80+$ ) no comprimento de onda de $630 \mathrm{~nm}$. Todas as determinações foram realizadas em triplicata. Os valores de absorbância foram convertidos em porcentagem de inibição de urease utilizando a equação 1: 
$I(\%)=100-\left[\left(A_{\text {inibidor }} / A_{\text {padrão }}\right) \times 100\right]$, onde: $(1)$

A inibidor: Valor da absorção apresentado no teste com óleo essencial;

A padrão: Valor da absorção apresentado no teste com o padrão (tiouréia).

Os valores de concentração inibitória média $\left(\mathrm{IC}_{50}\right)$ foram calculados utilizando $\mathrm{O}$ programa Microsoft Excel.

A composição química dos óleos essenciais foi estudada utilizando cromatografia gasosa acoplada à espectrometria de massas (CG-EM). As análises de CG-EM foram realizadas empregando-se um cromatógrafo Hewlett Packard 6890, acoplado a um detector seletivo de massas, operando com uma fonte de elétrons com energia de ionização de 70 eV. O cromatógrafo operava com coluna capilar de sílica fundida do tipo HP-5 (30 m x $0,25 \mathrm{~mm} \times 0,25 \mu \mathrm{m})$. Empregou-se hélio de alta pureza como gás de arraste, com fluxo de $1 \mathrm{~mL} / \mathrm{min}$. As análises foram realizadas com injetor operando a $250 \stackrel{\circ}{\circ}$ e interface a $280 \stackrel{\circ}{ } \mathrm{C}$. Os volumes injetados foram de $1 \mu \mathrm{L}$ de solução, sem divisão de fluxo. A identificação dos constituintes químicos dos óleos essenciais estudados foi realizada comparando-se o espectro de massas de cada componente com espectros de massas armazenados nos bancos de dados digitais
"NIST Mass Spectrometry Data Center" e "Spectral Database for Organic Compounds".

O estudo de ancoragem molecular foi realizado no software iGEMDOCK 2.1 (HSU et al., 2011), utilizando na seção "Prepare Binding Site" a opção "by current file". Os arquivos dos produtos naturais (ligantes) foram carregados em formato ".mol", as estruturas dos ligantes foram previamente otimizadas utilizando $O$ software $A C D$ ChemSketch. Os parâmetros foram ajustados para "Standard Docking", em que a população foi definida como 200 , as gerações como 70 e o número de soluções como 2 . As configurações padrão foram mantidas na seção "Scoring function". Para visualização e tratamento dos docking utilizou-se o programa UCSF Chimera 1.10.1.

\section{RESULTADOS}

O perfil da relação concentração e inibição enzimática dos quatro óleos essenciais avaliados mostrou-se semelhante ao perfil encontrado para o inibidor padrão (tiouréia). Utilizando a equação da linha de tendência obtida em cada um dos estudos calculou-se a concentração inibitória média (IC $\left.\mathrm{C}_{50}\right)$ para os óleos essenciais avaliados, cujos valores são apresentados na tabela 1. A composição química, em percentual, dos óleos essenciais avaliados é apresentada na tabela 2 . 
Tabela 1. Valores de $\mathrm{IC}_{50}$ para os óleos essenciais de $R$. officinalis, $C$. citratus,

C. winterianius e $C$. sinensis.

\begin{tabular}{lc}
\hline Óleo essencial/padrão & $\mathbf{I C}_{\mathbf{5 0}}(\mathbf{p p m})$ \\
\hline Rosmarinus officinalis & 789,7 \\
Cymbopogon citratus & 167,5 \\
Cymbopogon winterianius & 67,6 \\
Citrus sinensis & 60,7 \\
Tiouréia & 7,85 \\
\hline
\end{tabular}

Tabela 2. Composição química, em percentual, dos óleos essenciais de Rosmarinus officinalis, Cymbopogon citratus, Cymbopogon winterianus e Citrus sinensis.

\begin{tabular}{|c|c|c|c|c|c|}
\hline Composto & $\begin{array}{l}\text { Tempo de retenção } \\
\text { (min.) }\end{array}$ & R. officinalis & C. citratus & $\begin{array}{c}\text { C. } \\
\text { winterianus }\end{array}$ & C. sinensis \\
\hline $\begin{array}{l}\text { 6-metil-5-Hepten-2- } \\
\text { ona }\end{array}$ & 8,217 & - & 1,34 & - & - \\
\hline Sabineno & 6,408 & 8,52 & - & - & - \\
\hline Canfeno & 6,896 & 5,86 & - & - & - \\
\hline$\alpha$-Pineno & 7,841 & 3,22 & - & - & - \\
\hline$\beta$-Pineno & 8,327 & 1,10 & - & - & - \\
\hline$p$-Cimeno & 9,654 & 1,80 & - & - & - \\
\hline D-limoneno & 9,789 & 3,58 & - & 4,11 & 75,68 \\
\hline Eucaliptol & 9,985 & 32,23 & - & - & - \\
\hline 4-Nonanona & 11,591 & - & 0,29 & - & - \\
\hline cis-Verbenol & 11,935 & - & 1,94 & - & - \\
\hline Linalool & 12,848 & 1,52 & 1,35 & 1,12 & 0,73 \\
\hline $\begin{array}{l}\text { cis-Óxido de } \\
\text { limoneno }\end{array}$ & 14,293 & - & - & - & 2,74 \\
\hline $\begin{array}{l}\text { trans-Óxido de } \\
\text { limoneno }\end{array}$ & 14,504 & - & - & - & 3,05 \\
\hline Isopulegol & 14,871 & - & - & 1,97 & - \\
\hline Cânfora & 14,971 & 26,26 & - & - & - \\
\hline Isoborneol & 15,436 & 2,11 & - & - & - \\
\hline Citronelal & 15,558 & - & - & 21,10 & - \\
\hline Borneol & 15,855 & 3,04 & - & - & - \\
\hline$\alpha$-Terpineol & 16,962 & 1,83 & - & - & - \\
\hline Decanal & 17,592 & - & - & 0,16 & - \\
\hline Citronelol & 18,926 & - & - & 12,84 & - \\
\hline trans-Carveol & 18,276 & & & & 3,85 \\
\hline Carvona & 19,403 & & & & 3,82 \\
\hline Neral & 19,728 & - & 21,51 & 0,42 & - \\
\hline Geraniol & 20,451 & - & 8,05 & 20,94 & - \\
\hline Geranial & 21,253 & - & 27,93 & - & - \\
\hline Acetato de bornila & 21,373 & 3,00 & - & - & - \\
\hline Nerol & 25,808 & - & 4,71 & 5,58 & - \\
\hline$\beta$-Cariofileno & 27,280 & 2,89 & 2,54 & - & - \\
\hline$m$-Eugenol & 28,569 & - & 0,37 & 1,33 & - \\
\hline Humuleno & 28,729 & 0,42 & 0,29 & - & - \\
\hline Metil $m$-Eugenol & 30,606 & - & - & 0,48 & - \\
\hline$\delta$-Cadineno & 31,328 & - & 1,64 & - & - \\
\hline$\gamma$-Muruleno & 31,676 & - & 0,55 & 2,50 & - \\
\hline$\alpha$-Elemol & 32,809 & - & - & 4,06 & - \\
\hline Nerolidol & 33,106 & - & - & 0,37 & - \\
\hline Óxido de cariofileno & 34,133 & - & 0,46 & - & - \\
\hline
\end{tabular}




\begin{tabular}{lccccc} 
t-Cadinol & 36,436 & - & - & 1,01 & - \\
Eudesmol & 36,767 & - & - & 0,31 & - \\
$\alpha$-Cadinol & 36,935 & - & - & 1,18 & - \\
Miristato de & 43,025 & - & 1,00 & - & - \\
isopropila & & & 0,91 & - & - \\
Nonadecanol & 44,927 & - & 2,90 & - & $\mathbf{8 9 , 8 7}$ \\
Esqualeno & 68,752 & - & $\mathbf{7 7 , 7 8}$ & $\mathbf{7 9 , 4 8}$ & \\
& Total & $\mathbf{9 7 , 3 8}$ & & \\
\hline
\end{tabular}

Os resultados de ancoragem limoneno estão ancorados no sítio ativo da molecular dos constituintes majoritários dos óleos essenciais estudados na enzima urease (PDB 1E9Z) são apresentadas nas figuras 1 urease, apresentando energia de interação ligante-enzima de $-73,78,-71,79$ e $-57,39$ $\mathrm{kcal} / \mathrm{mol}$, respectivamente.

4. Os compostos eucaliptol, geranial e D-
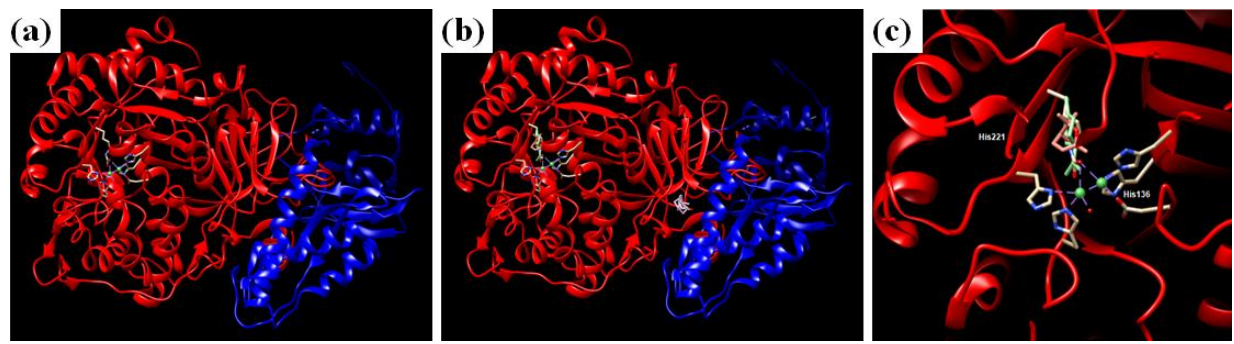

Figura 1. (a) Estrutura da enzima urease; (b) localização dos compostos majoritários do óleo essencial de $R$. officinalis após o estudo de ancoragem molecular; (c) Eucaliptol e $D$-limoneno interagindo no sítio ativo da enzima urease.
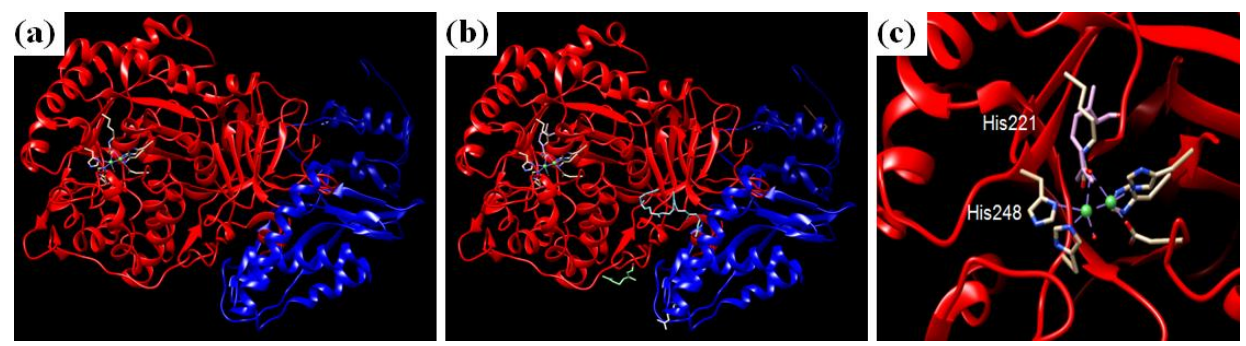

Figura 2. (a) Estrutura da enzima urease; (b) localização dos compostos majoritários do óleo essencial de $C$. citratus após o estudo de docagem molecular; (c) geranial interagindo no sítio ativo da enzima urease. 

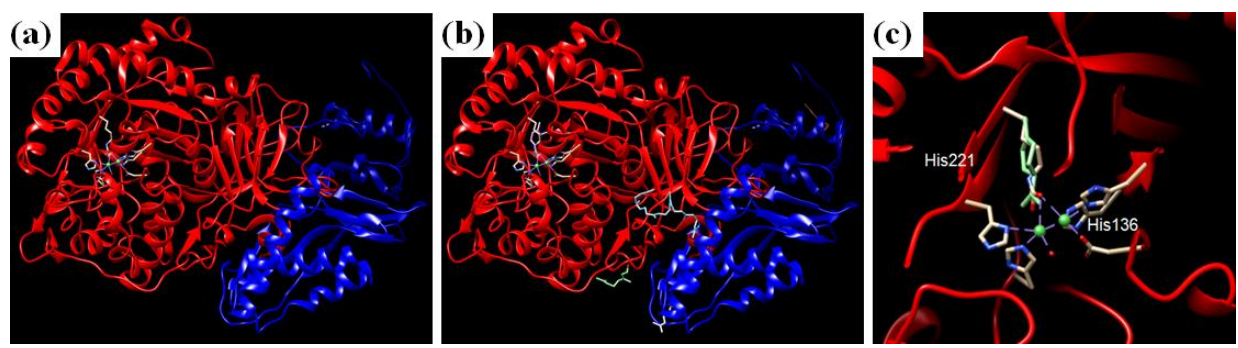

Figura 3. (a) Estrutura da enzima urease; (b) localização dos compostos majoritários do óleo essencial de $C$. winterianius após o estudo de docagem molecular; (c) D-limoneno interagindo no sítio ativo da enzima urease.
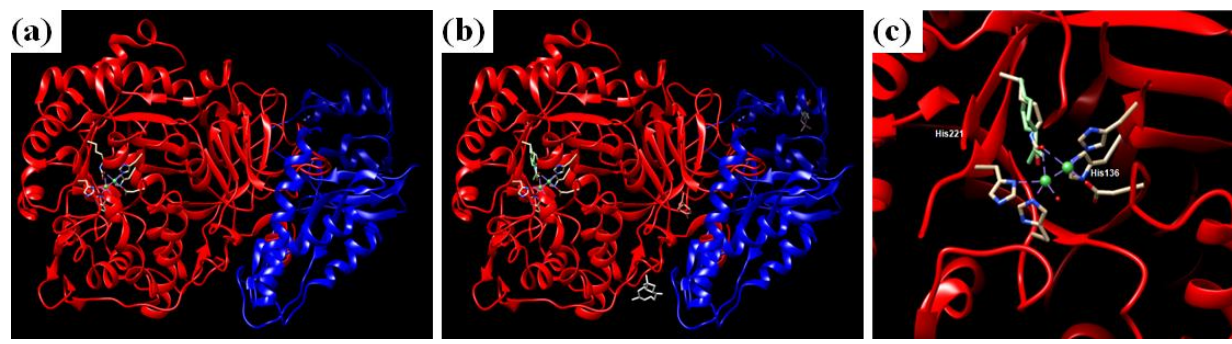

Figura 4. (a) Estrutura da enzima urease; (b) localização dos compostos majoritários do óleo essencial de $C$. sinensis após o estudo de docagem molecular; (c) D-limoneno interagindo no sítio ativo da enzima urease.

\section{DISCUSSÃO}

Pode-se observar que os óleos essenciais de Rosmarinus officinalis, Cymbopogon citratus, Cymbopogon winterianius e Citrus sinensis foram capazes de inibir a atividade da enzima urease, embora tenham apresentado grande variação de $\mathrm{IC}_{50}(60,7$ - 789,7 ppm). 0 estudo da relação concentração de tiouréia e porcentagem de inibição revela um comportamento logarítmico para a linha de tendência, tal como relatado na literatura (BIGLAR et al., 2012).

O estudo por CG-EM revelou que os óleos essenciais estudados são constituídos principalmente por terpenos e fenilpropanóides. Várias atividades biológicas/farmacológicas foram comprovadas para diferentes óleos essenciais, tais como anti-inflamatória, inseticida, antimicrobiana, antitumoral, antiviral, imunomoduladora, anticonvulvante, antiespamódica e ansiolítica. A maioria dessas atividades biológicas/farmacológicas são atribuídas aos terpenóides constituintes dos óleos essenciais (ROMERO; ROMERO, 2014). O Dlimoneno, por exemplo, monoterpeno encontrado em vários óleos essenciais, apresentou, em testes in vitro, atividade inibidora de H. pylori (ROZZA et al., 2011). 
Os resultados obtidos nos estudos de ancoragem molecular sugerem que os compostos eucaliptol, geranial e D-limomeno podem atuar como inibidores da enzima urease por interagir no sítio ativo, tal como relatado para a tiouréia e outros inibidores reconhecidos para esta enzima. Observa-se que os três monoterpenos mencionados interagem, através de interações de van der Waals, com o resíduo His221, apontado na literatura como importante para a ancoração da uréia no sítio ativo da urease (DIXON et al., 1980). Estes resultados sugerem que a atividade inibidora de urease apresentada pelos óleos essenciais estudados pode ocorrer por um mecanismo de inibição reversível competitivo. Além da inibição enzimática através da interação de ligantes no sítio ativo é possível que os constituintes dos óleos essenciais realizem a inibição da urease por outros mecanismos.

\section{CONCLUSÃO}

Os resultados apresentados neste trabalho indicam que óleos essenciais podem ser considerados fontes promissoras de substâncias bioativas inibidoras de urease. Dentre as nove amostras avaliadas determinou-se que os óleos essenciais de Rosmarinus officinalis, Cymbopogon citratus, Cymbopogon winterianius e Citrus sinensis são promissores inibidores de urease. Sendo assim, estudos posteriores são necessários para verificar se in vivo estes óleos apresentarão efeito sobre a bactéria $H$. pylori.

\section{REFERÊNCIAS}

BIGLAR, M. et al. A preliminary investigation of the jack-bean urease inhibition by randomly selected traditionally used herbal medicine. Iranian Journal of Pharmaceutical Research, Tehran, v.11, n.3, p.831-837, 2012.

COELHO, L. G. V.; ZATERKA, S. (Org.). II Consenso Brasileiro sobre Helicobacter pylori. Arq. Gastroenterol., São Paulo, v.42, n.2, p.128-132, abr./jun. 2005.

COELHO, F. M. M. C. Helicobacter pylori Eficácia da terapêutica. 2013. 60f. Dissertação (Mestrado) - Ciências da Saúde, Universidade da Beira Interior, Covilhã.

DIXON, N. E. et al. Jack bean urease (EC 3.5.1.5). V. On the mechanism of action of urease on urea, formamide, acetamide, $\mathrm{N}$ methylurea, and related compounds. Can. J. Biochem. Cell Biol., Ottawa, v.58, n.12, p.1335-1344, dez. 1980.

HARVEY, A. L. Natural products in drug discovery. Drug Discovery Today, Glasgow, v.13, n.19, p.894-897, out. 2008. http://dx.doi.org/10.1016/j.drudis.2008.07.0 04

HSU, K.-C. et al. iGEMDOCK: a graphical environment of enhancing GEMDOCK using pharmacological interactions and postscreening analysis. BMC Bioinformatics, Londres, v.12, (Suppl 1), p.S33, fev. 2011. http://dx.doi.org/10.1186/1471-2105-12-S1S33

LADEIRA, M. S. P. et al. Biopatologia do Helicobacter pylori. Jornal Brasileiro de Patologia e Medicina Laboratorial, Rio de Janeiro, v.39, n.4, p.335-342, mar. 2003. 
PINTO, A. C. R. Helicobacter pylori: uma revisão. 2007. 62 f. Monografia (Trabalho de Conclusão de Curso) - Centro Universitário das Faculdades Metropolitanas Unidas, São Paulo, SP.

ROMERO, R. B.; ROMERO, A. L. Inibição de Ciclooxigenases 1 (COX-1) e 2 (COX-2) por Monoterpenos: um Estudo in Silico. UNOPAR Cient. Ciênc. Biol. Saúde, Londrina, v.16, n.4, p.307-316, jun. 2014.

ROZZA, A. L. et al. Gastroprotective mechanisms of Citrus lemon (Rutaceae) essential oil and its majority compounds limonene and pinene: Involvement of heatshock protein-70, vasoactive intestinal peptide, glutathione, sulfhydryl compounds, nitric oxide and prostaglandin E2. ChemicoBiological Interactions, v.189, n.1-2, p.82-89, jan.

2011.

http://dx.doi.org/10.1016/j.cbi.2010.09.031

SIQUEIRA, J. S. et al. Aspectos gerais nas infecções por Helicobacter pylori - revisão. Revista Brasileira de Análises Clínicas, Rio de Janeiro, v.39, n.1, p.9-13, jan./mar. 2007.

SOUZA, F. R. C. Infecção por Helicobacter pylori - da epidemiologia ao tratamento. 2013. 50 f. Dissertação (Mestrado em Ciências Biomédicas). Universidade do Porto, Porto.

WeAtherburn, M. W. Phenol - Hypoclorite Reaction for Determination of Ammonia. Analytical Chemistry, Ottawa, v.39, n.8, p.971-974, jul. 1967. http://dx.doi.org/10.1021/ac60252a045 